\title{
Liquid crystal polymer networks : preparation, properties, and applications of films with patterned molecular alignment
}

\section{Citation for published version (APA):}

Liu, D., \& Broer, D. J. (2014). Liquid crystal polymer networks : preparation, properties, and applications of films with patterned molecular alignment. Langmuir, 30(45), 13499-13509. https://doi.org/10.1021/la500454d

DOI:

10.1021/la500454d

Document status and date:

Published: 01/01/2014

\section{Document Version:}

Publisher's PDF, also known as Version of Record (includes final page, issue and volume numbers)

\section{Please check the document version of this publication:}

- A submitted manuscript is the version of the article upon submission and before peer-review. There can be important differences between the submitted version and the official published version of record. People interested in the research are advised to contact the author for the final version of the publication, or visit the $\mathrm{DOI}$ to the publisher's website.

- The final author version and the galley proof are versions of the publication after peer review.

- The final published version features the final layout of the paper including the volume, issue and page numbers.

Link to publication

\section{General rights}

Copyright and moral rights for the publications made accessible in the public portal are retained by the authors and/or other copyright owners and it is a condition of accessing publications that users recognise and abide by the legal requirements associated with these rights.

- Users may download and print one copy of any publication from the public portal for the purpose of private study or research.

- You may not further distribute the material or use it for any profit-making activity or commercial gain

- You may freely distribute the URL identifying the publication in the public portal.

If the publication is distributed under the terms of Article 25fa of the Dutch Copyright Act, indicated by the "Taverne" license above, please follow below link for the End User Agreement:

www.tue.nl/taverne

Take down policy

If you believe that this document breaches copyright please contact us at:

openaccess@tue.nl

providing details and we will investigate your claim. 


\title{
Liquid Crystal Polymer Networks: Preparation, Properties, and Applications of Films with Patterned Molecular Alignment
}

\author{
Danqing Liu ${ }^{\dagger}$ and Dirk J. Broer*, ${ }^{\dagger, \dagger}$ \\ ${ }^{\dagger}$ Laboratory of Functional Organic Materials \& Devices (SFD), Department of Chemical Engineering \& Chemistry, Eindhoven \\ University of Technology, Den Dolech 2, 5612 AZ Eindhoven, The Netherlands \\ ${ }^{*}$ Institute for Complex Molecular Systems (ICMS), P.O. Box 513, 5600 MB Eindhoven, The Netherlands
}

ABSTRACT: Monolithically ordered liquid crystal polymer networks are formed by the photoinitiated polymerization of multifunctional liquid crystal monomers. This paper describes the relevant principles and methods, the basic structureproperty relationships in terms of mesogenic properties of the monomers, and the mechanical and optical properties of the polymers. Strategies are discussed to control the molecular orientation by various means and in all three dimensions. The versatility of the process is demonstrated by two examples of films with a patterned molecular order. It is shown that patterned retarders can be made by a two-step polymerization process which is successfully employed in a transflective display principle. A transflective display is a liquid crystal display that operates in both a reflective mode using ambient light and a transmissive mode with light coming from a backlight system. Furthermore, a method is discussed to create a patterned film in a single polymerization process. This film has alternating planar chiral nematic areas next to perpendicularly oriented (so-called homeotropic) areas. When applied as a coating to a substrate, the film changes its surface texture. During exposure to UV light, it switches from a flat to a corrugated state.

\section{INTRODUCTION}

Polymers with a well-controlled molecular positioning in all three dimensions attract considerable attention due to their unusual but very accurately adjustable and addressable optical, electrical, and mechanical properties. A general approach to obtaining well-ordered polymer networks is through the photoinitiated polymerization of liquid crystal (LC) monomers. ${ }^{1-4}$ Figure 1 illustrates this process schematically. Working with low-molecular-weight reactive mesogens provides a wide variety of self-organizing molecular configurations. Figure 1 shows examples of twisted nematic (TN), splay bend, tilted uniaxial, and chiral nematic (cholesteric) alignments. Next to nematic LC phases, where the molecules exhibit only orientational order, the monomers can also be processed in one of their smectic phases. The smectic phases have not only orientational order but also positional order by organizing the molecules within layers. All of these types of molecular order, benefiting from a plurality of alignment techniques and phases, can be locked into a polymer network by a photopolymerization procedure. $^{5-8}$ Photopolymerization proceeds very fast, which has the advantage that phase separation and phase transitions during polymerization are kinetically suppressed.

Known techniques to establish monolithic molecular order in LCs are rubbed polymer (usually polyimide) surfaces, surfactant-treated surfaces, external electric or magnetic fields, and flow. Interestingly, they can often be combined to create coatings with even more complex molecular architectures. ${ }^{9}$

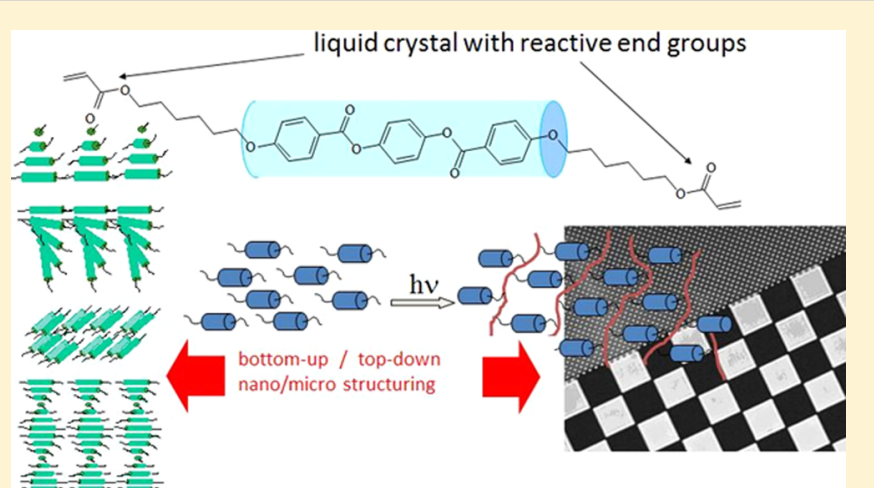

Structures can be printed, and the photopolymerization process allows local polymerization via a photomask to obtain structures down to a length scale of micrometers. The combination of the self-organization of LCs and local (lithographic) polymerization is a good example of combined bottom-up and top-down structuring technology, as shown in Figure 1., 10 The molecular structure, of which Figure 1 shows an example, can be tailored to meet specific requirements with respect to mechanical or optical properties. Most often a blend of LC monomers is used to adjust the monomeric properties further (e.g., to adjust the temperature range in which the monomers are liquid crystalline or to optimize the viscosity of the mixture) and also to enhance further the polymeric properties (e.g., by optimizing the cross-link density by the right ratio of mono- and difunctionalized LC monomers). This affects the elastic modulus and the glass-transition temperature $\left(T_{\mathrm{g}}\right)$ of the polymer coating or film, as shown in ref 21 .

\section{LIQUID CRYSTAL MONOMERS}

The monomers that are exploited for photopolymerization have a structure similar to traditional liquid crystals (i.e., they have an anisotropic shape often with a stiff central core which has either a rodlike or a disklike nature). Thousands of different LC

Received: February 3, 2014

Revised: April 2, 2014

Published: April 7, 2014 

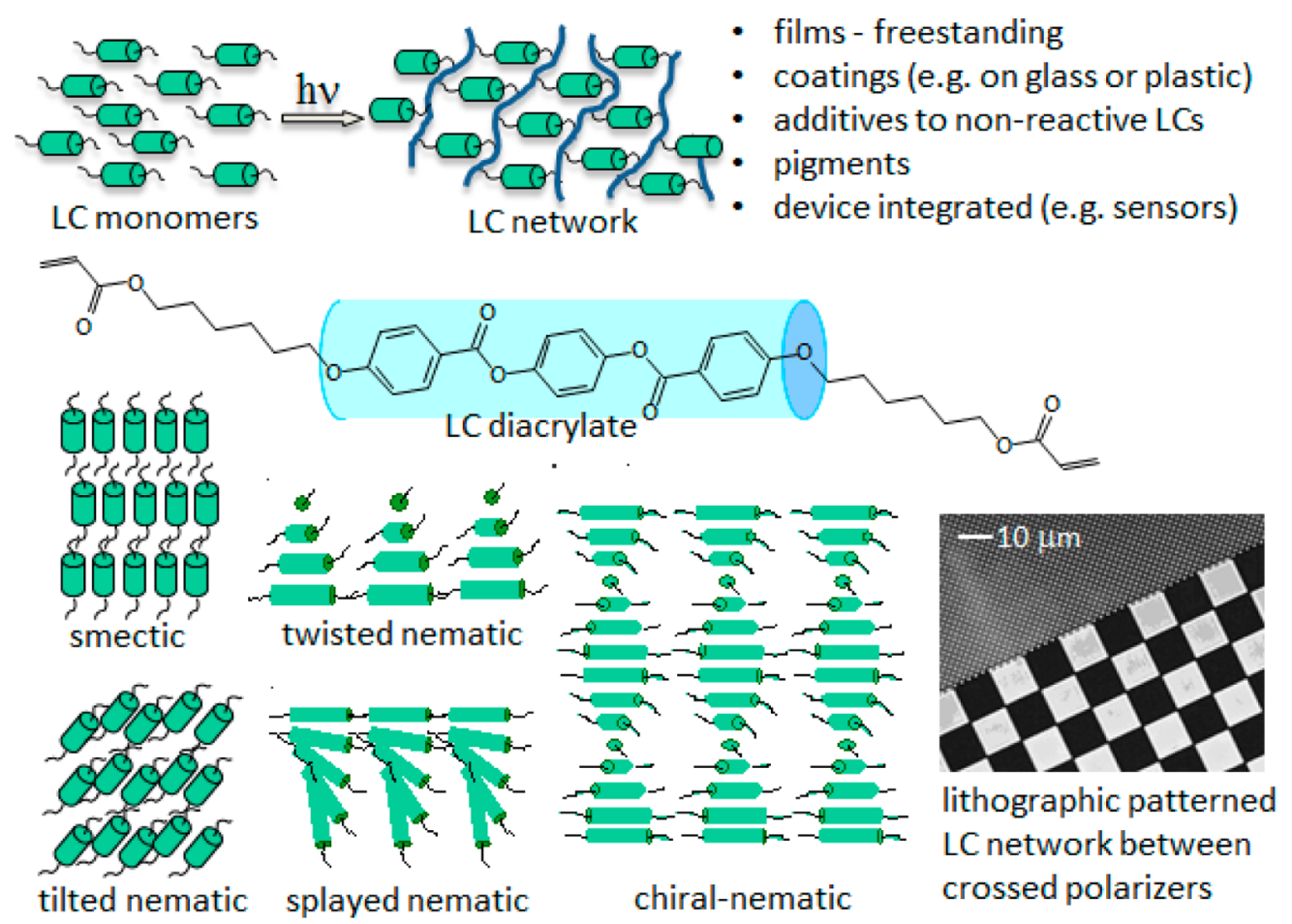

Figure 1. Schematic illustration of the formation of an LC network and an example of an LC monomer. Different types of alignment can be established by surface orientation techniques and chiral additives and can be locked in a polymer with the shape adjusted to its application. The polarization microscopy image shows micrometer structures created by two-step polymerization in the nematic phase using a photomask and the isotropic-phase photomask via flood exposure at elevated temperatures.

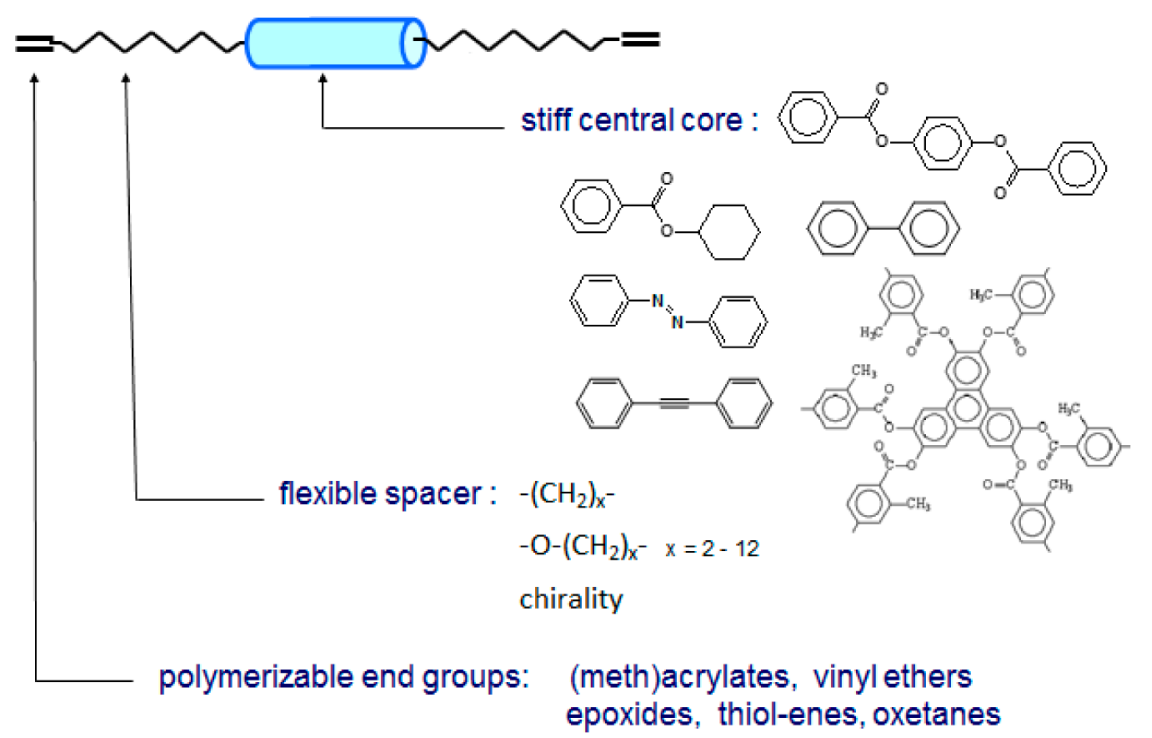

Figure 2. Schematic structure of difunctional liquid crystal monomers. Some examples are given for the stiff central core, the flexible side groups, and the polymerizable end groups.

molecules are known and can be found in the table book of Demus and Zaschke. ${ }^{11}$ In addition to the generic structure, the LC monomers have polymerizable groups which are attached either at the far end(s) ${ }^{12}$ or as a lateral side group. ${ }^{13}$ Also the LC molecules can have either one, two, or more functional groups. Figure 2 gives a schematic overview of the molecular design of cross-linking LC monomers with two functional groups. And although many polymerizable groups have been studied, by far the most used are the acrylates and the methacrylates because of their high rate of polymerization when exposed to UV light in the presence of a small concentration of a free-radical-generating photoinitiator.

Figure 3 gives an overview of a selection of LC acrylate molecules. One might observe that they all have a crystalline melting temperature above RT. This means that for processing in the melt the monomers must be heated, which has the risk of premature polymerization. To stabilize the monomers, they are blended with free radical scavengers. At a low concentration, these scavengers inhibit thermal polymerization, but when the photoinitiator is exposed to UV light, the excess free radicals 

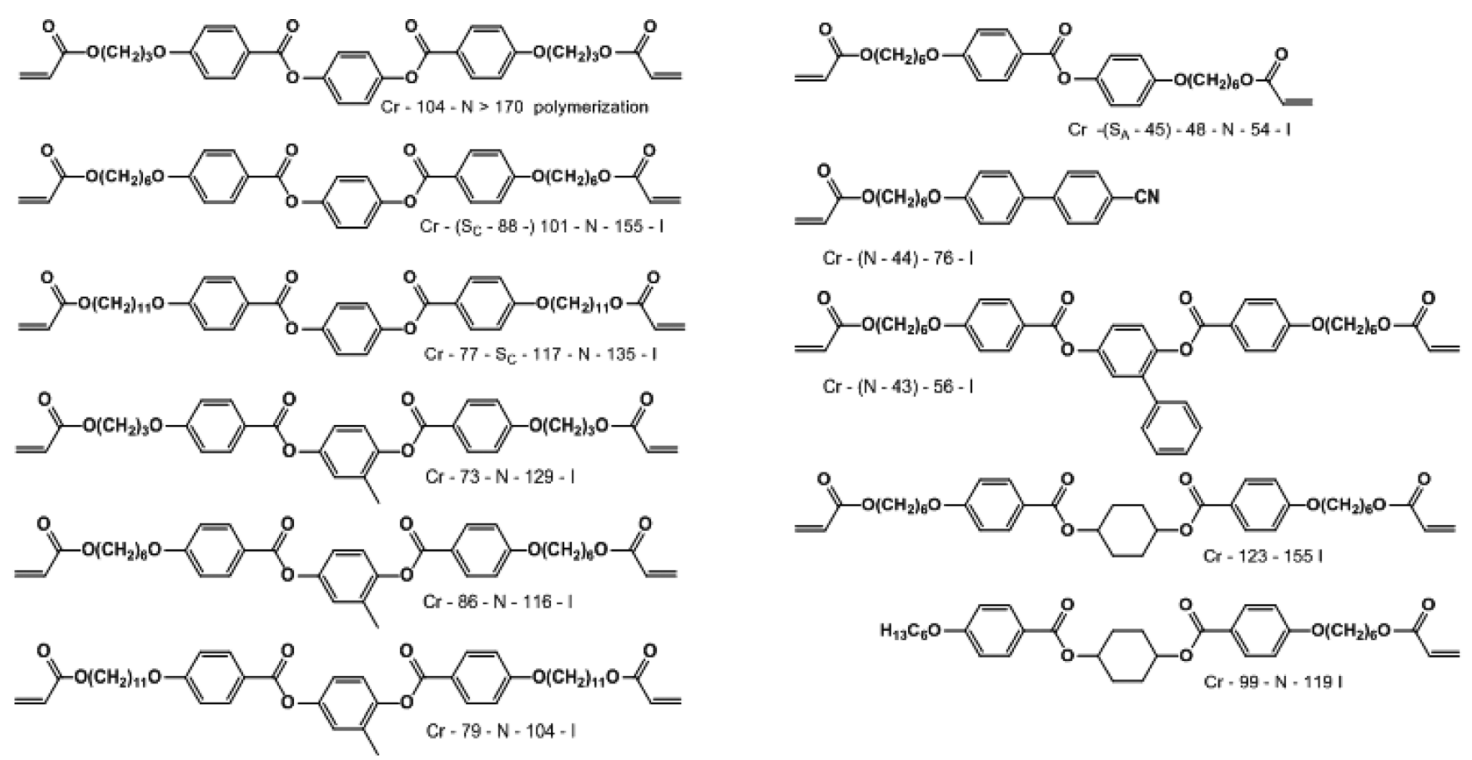

Figure 3. Some examples of LC acrylate monomers and their phase behavior. Cr refer to crystalline, $S_{A}$ and $S_{C}$ refer to smectic A and smectic C, N refers to nematic, and I refers to isotropic. The numbers in between are the transition temperatures in Celsius. The data between brackets refer to phases observed only during the supercooling of the samples (data from ref 11).
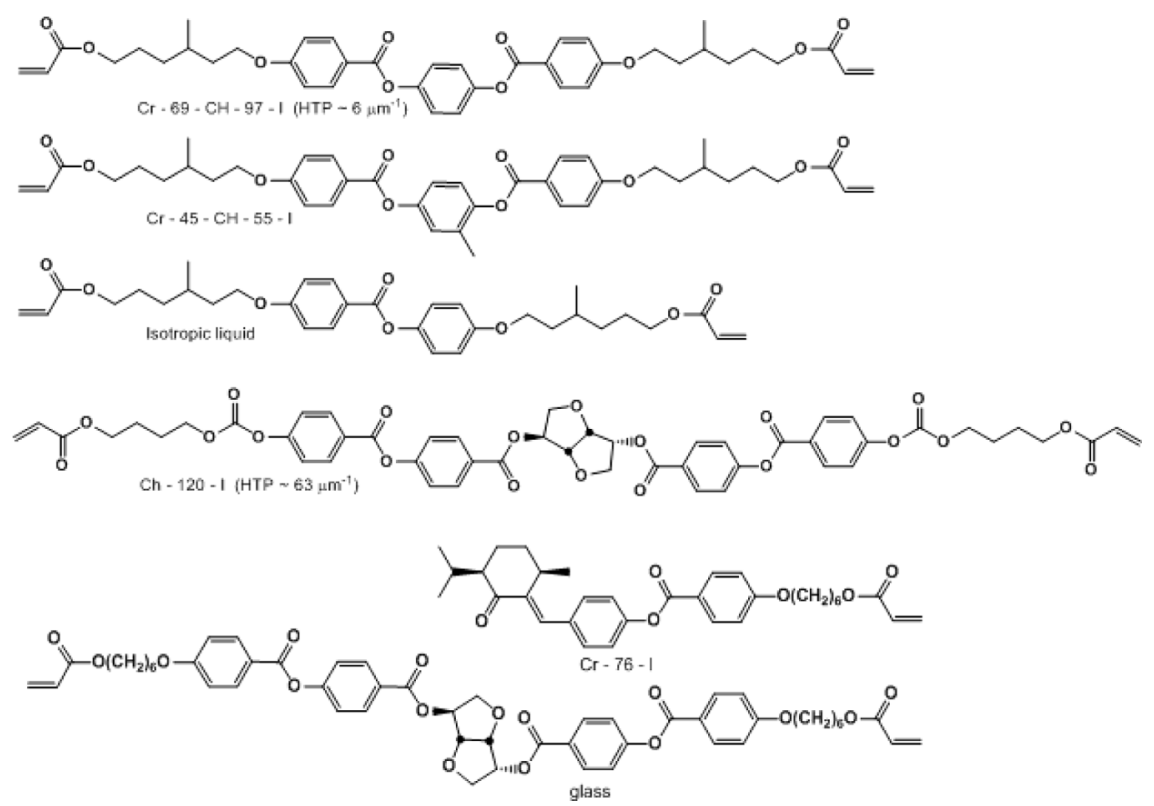

Figure 4. Some examples of chiral nematic LC acrylate monomers and their phase behavior. $\mathrm{CH}$ refer to the chiral nematic (cholesteric) phase (data from ref 11).

take over control of the polymerization. An efficient inhibitor is p-methoxyphenol. It is usually added in a concentration of 100 to $200 \mathrm{ppm}$. From Figure 3, a few trends can be observed that are also known for common, nonreactive liquid crystals (e.g., reducing the aspect ratio of the molecule destabilizes the formation of a liquid crystal phase). Therefore, two ring systems often form monotropic liquid phases that can be observed only during supercooling from the isotropic melt. For similar reasons, lateral substituents on the central ring give lower liquid crystal to isotropic temperatures and destabilize smectic phase formation. Nevertheless, the use of small side groups is often popular because it also reduces the melting temperatures, which makes processing in the LC phase easier without the risk of premature thermal polymerization. Increasing the length of the flexible spacer tends to stabilize the formation of smectic phases. A small odd/even effect is observed with respect to spacer length where the LC phase is somewhat more stabilized when the end groups are aligned along the molecular long axis.

A special case of the nematic phase is the chiral nematic phase, often referred to as the cholesteric phase. Some examples are given in Figure 4. The chirality makes the director describe a helix perpendicular to the average orientation of the long axes of the molecules, as schematically shown in Figure 1. Also, this chiral nematic order is frozen in by the photopolymerization process, which is nicely demonstrated in Figure 5. It shows a scanning electron microscope photograph of a cross section of the polymeric chiral nematic network. ${ }^{14}$ The periodicity of the apparent layers equals half of the pitch $p$ of the chiral nematic helix. The layerlike structure is 


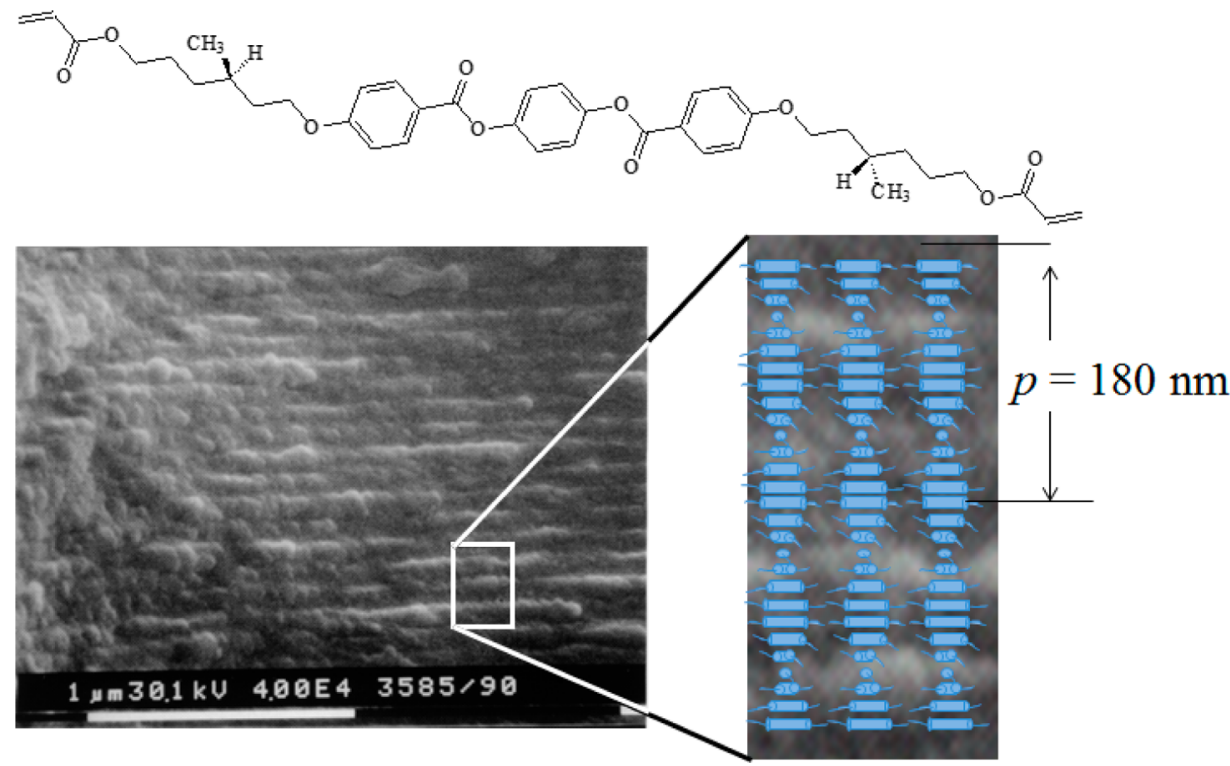

Figure 5. Scanning electron microscope picture of the cross section of a fractured film of a chiral nematic LC acrylate polymer network.
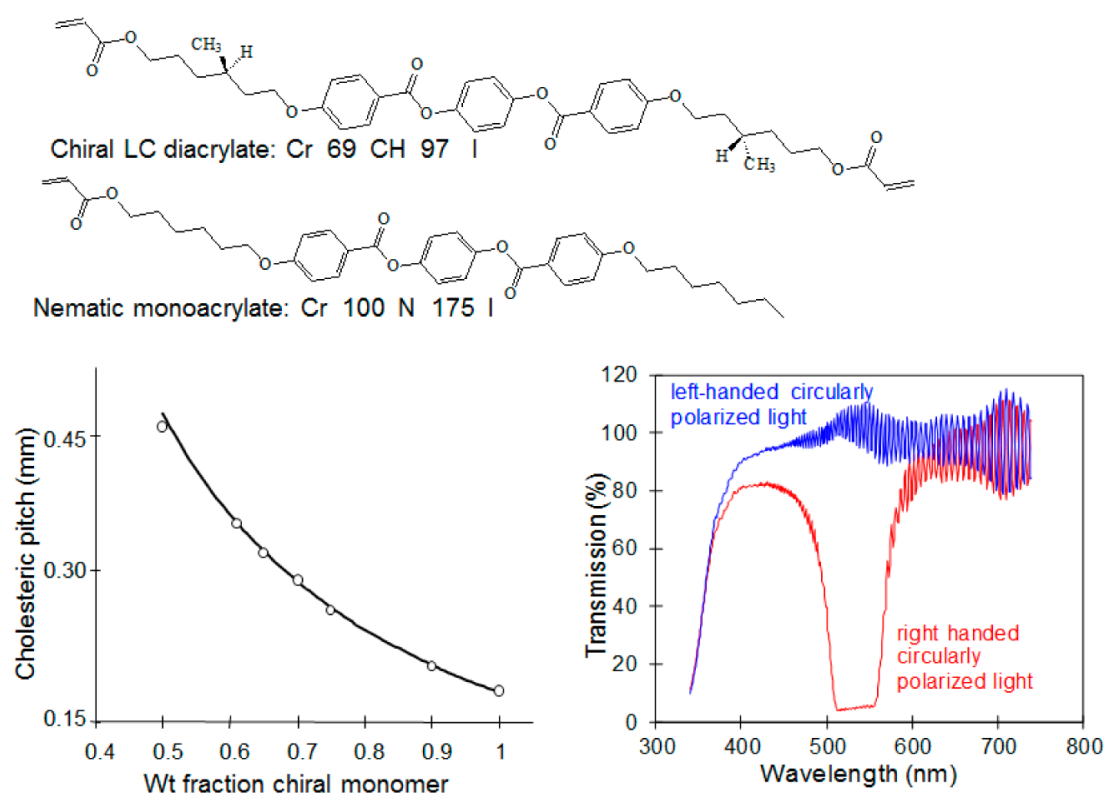

Figure 6. Pitch as a function of the composition of a blend of a chiral nematic and a nematic monomer after polymerization (left) and the transmission spectrum of a $40 / 60 \mathrm{w} / \mathrm{w}(\mathrm{N} / \mathrm{Ch})$ blend measured with circularly polarized light.

formed by the difference in fracture texture depending on the average orientation of the LC molecular units. From this figure, it can be derived that when this monomer is polymerized the resulting film has a pitch of $180 \mathrm{~nm}$.

In many cases, the chiral monomers are added as a guest additive to a nematic monomer host. The pitch can then be accurately adjusted by the blending ratio between the chiral and the nematic monomer. Of special interest are those blending ratios where the pitch has a value on the order of the wavelength of visible light. In this case, the chiral nematic LCs have the ability to reflect circularly polarized light of the same handedness ${ }^{15}$ as that of the molecular helix and with a reflection wavelength $\lambda$ that scales with the pitch $p$ through the in-plane average index $\bar{n}: \lambda=\bar{n} p$. An example of a monomer blend and its corresponding pitch and reflection wavelength is shown in Figure 6. The bandwidth of the reflection band scales with the birefringence of the monomer by $\Delta \lambda=\Delta n p$. Often, $\Delta \lambda$ is between 40 and $80 \mathrm{~nm}$ in the visible part of the spectrum. It is possible to expand it, for instance, to cover the visible wavelength range. In that case, special procedures are necessary. ${ }^{16,17}$ The ability of the chiral molecules to induce a molecular helix is quantified by the so-called helical twisting power (HTP), which is defined as $\mathrm{HTP}=(p c)^{-1}$ where $c$ is the concentration of chiral dopant and assuming that the dopant consists of one enantiomer. Some HTP values can be found in Figure 4.

\section{PROCEDURES TO FORM LIQUID CRYSTAL POLYMER NETWORKS}

Prior to polymerization, we need to mix the LC monomer(s) with a photoinitiator optimized to the curing wavelength. Usually only a small amount is used (e.g., 1 wt \%). This 
addition hardly changes the LC transition temperatures. ${ }^{4}$ Homogeneous mixtures are obtained by -dissolving all of the components in a strong solvent such as dichloromethane, xylene, or tetrahydrofuran, which is subsequently evaporated. Thin films are formed by processing either from solution or in the melt. In most cases, pretreated substrates are used, such as glass provided with a thin (e.g., $30 \mathrm{~nm}$ ) rubbed polyimide coating to establish the planar LC monomer orientation or glass treated with a surfactant to orient the LC monomers perpendicular to the substrate. Complex orientation profiles are obtained when an LC melt is brought between two differently treated substrates (e.g., by capillary filling). In this way, splayed and twisted nematic orderings are easily obtained, as was already suggested in Figure 1. In fact, many alignment methods are developed for the display industry, and they all can be adapted in this process of the polymerization of LC monomers prior to UV exposure. When use is made of single substrate technologies, for instance, to form structures by inkjet printing, the orientation can be further controlled by the addition of small amounts of a surfactant such as a fluorinated acrylate.

When the LC monomers are brought to their desired organization, photopolymerization is initiated by exposure to light. Depending on the selected photoinitiator, either UV or visible light can be applied. And in the case of free-radical polymerization (as is the case with LC acrylates), the polymerization preferably takes place shielded from oxygen to avoid oxygen inhibition. Under this condition, polymerization occurs by exposure to a relatively low intensity lamp source. For instance, in the presence of 1 wt $\% \alpha, \alpha$-dimethoxy- $\alpha$ phenylacetophenone (Irgacure 651, Ciba (now part of BASF)), the polymerization of LC diacrylate proceeds within seconds by exposure to a $365 \mathrm{~nm}$ fluorescent lamp with an on-sample intensity of $5 \mathrm{~mW} \cdot \mathrm{cm}^{-2}$. The photopolymerization in general is a high conversion process, especially when carried out at elevated temperatures. However, if the curing is performed at room temperature, then vitrification can take place during the polymerization process. This limits monomer mobility, and further reaction of the unreacted groups is obstructed. It is therefore in such case recommended to provide a postcure at a temperature around or just above the glass-transition temperature. Usually heating to $120^{\circ}$ for $10 \mathrm{~min}$ carried out just after UV exposure is sufficient for fully polymerization. The polymerization rate scales with the intensity of light (i.e., higher intensities lead to faster rates). However, one should avoid increasing the sample temperature too much at higher intesities as this lead to changes in order, either by a reduction in order or by full conversion to the isotropic state.

Photopolymerization is a single-step polymerization process that directly leads to an aligned and basically defect-free polymer film. It differs from the cross-linked LC elastomer counterpart where the formed prepolymer needs to be stretched in order to form the desired aligned state which is subsequently fixed by cross-linking in the stretched state. ${ }^{18,19}$ The photopolymerization of oriented monomers has another advantage. The LC film can be formed directly at or between substrates that are part of the final device. By photopolymerization, the molecular orientation is in general preserved, although the degree of order might be somewhat affected by the molecular packing when the monomers are being densified during the formation of the polymer chains. ${ }^{2,20}$ The polymerization shrinkage is normally between 3 and 8 vol $\%$ depending on the molecular weight and the curing temperature and is anisotropic with the highest shrinkage along the orientation direction. When applied as an adhering coating to a substrate, this might lead to some built-up stress, especially parallel to the orientation.

\section{POLYMER PROPERTIES}

Optical Properties. Like low-molar-mass liquid crystals, the LC monomers are highly birefringent with a high refractive index when measured with light polarization parallel to the director and a lower index when measured orthogonally., ${ }^{2,4}$ Figure 7 shows the ordinary $\left(n_{0}\right)$ and extraordinary $\left(n_{\mathrm{e}}\right)$

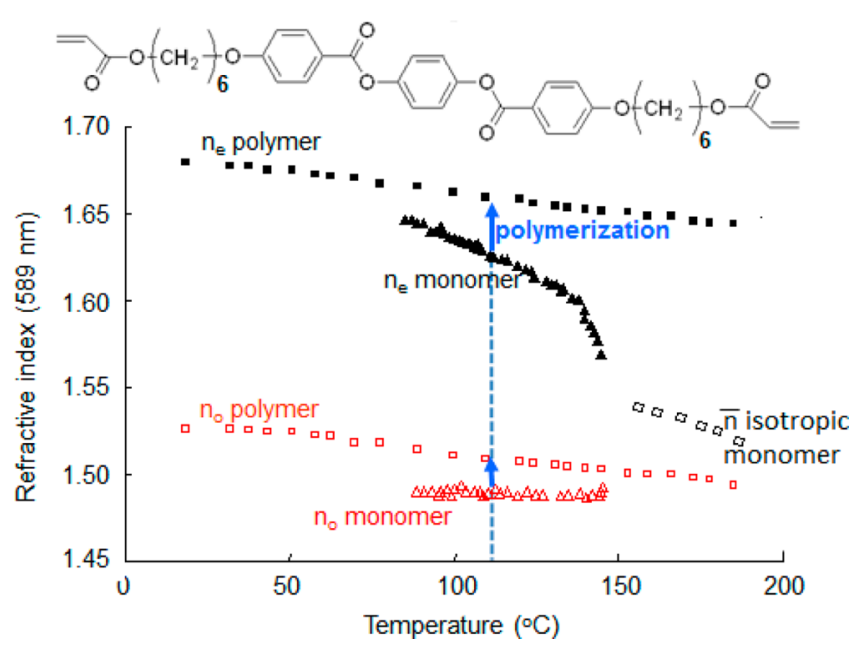

Figure 7. Refractive indices measured by a Abbe refractometer before and after polymerization of the LC diacrylate. The arrows indicate the polymerization temperature showing an increase in both $n_{0}$ and $n_{\mathrm{e}}{ }^{2}$

refractive indices of an LC monomer and of its polymer, respectively. The monomer behaves as a traditional low-molarmass nematic LC with a large temperature dependence near the transition from the nematic to the isotropic phase. During polymerization at $110{ }^{\circ} \mathrm{C}$, both $n_{0}$ and $n_{\mathrm{e}}$ increase because of an increase in density (polymerization shrinkage ${ }^{19}$ ), and $n_{\mathrm{e}}$ increases somewhat more because in this particular case the order parameter also increases slightly. Most interestingly, no isotropic phase is formed upon further heating of the polymer to thermal degradation, and the birefringence $\Delta n=n_{\mathrm{e}}-n_{0}$ is only marginally reduced. This behavior is observed for all LC diacrylates. A larger temperature dependence is found for the systems with larger spacer lengths or lower cross-link densities. Birefringence values are most often found between 0.05 and 0.25 depending on the aromaticity of the monomers and the eventual incorporation of strong dipoles (cyano group or halogen substituents). Modifying the LC monomer with $\pi$ conjugating groups between the aromatic rings increases the birefringence further. For instance, the introduction of tolane moieties in the stiff central chain (Figure 2) increase $\Delta n$ to values around 0.6 , which is extremely high for polymer networks in general.

Polymer Mechanical Properties. Unlike liquid crystal main-chain polymers such as the aramids, the LC polymer networks do not exhibit extraordinary properties with respect to the elastic modulus or strength. Figure 8 gives some examples. In general, the modulus is around a few GPa's and the strength is 10 to $100 \mathrm{MPa}$. Those values are also quite common for isotropic photo-cross-linked polymer networks. The modulus is anisotropic but is not more than a factor of 3 higher when measured along the director than when measured 


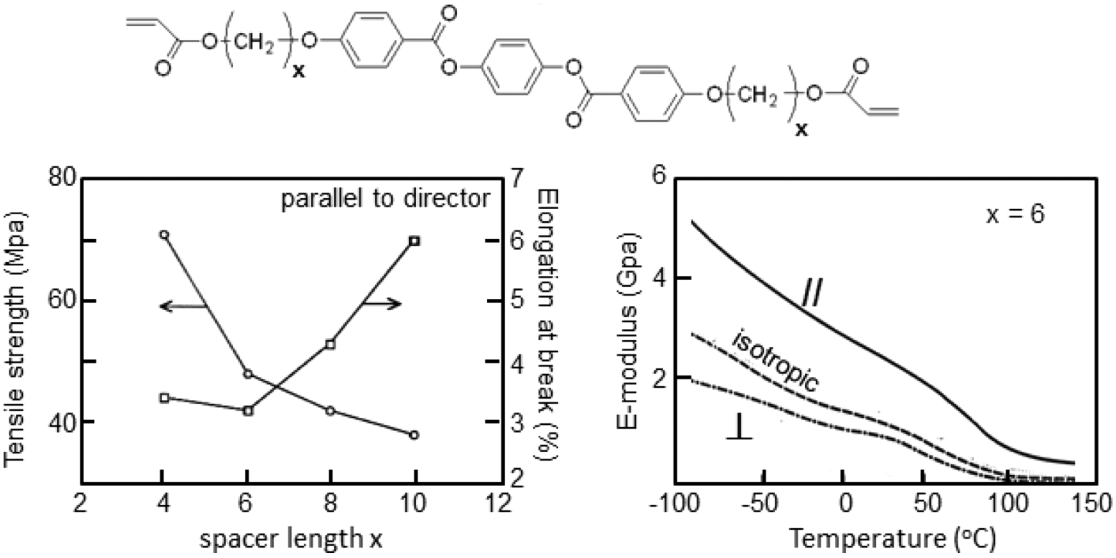

Figure 8. Mechanical properties of polymer networks made by photopolymerization of the monomer shown. The strength and elongation at the break are measured parallel to the director. The Young's modulus is measured parallel and perpendicular to the director and at a polymer film that was polymerized in the isotropic state of the monomer (data from ref 21).

perpendicular to it. ${ }^{20}$ The glass transition $T_{\mathrm{g}}$ of the six-spacered sample, as determined by dynamic mechanic measurement at a frequency of $1 \mathrm{~Hz}$, is around $80^{\circ} \mathrm{C}$, a value which increases for shorter spacers.

Of more interest than the strength and modulus is the anisotropic thermal expansion of the oriented LC networks. ${ }^{22}$ Not only is the majority of covalent bonds more or less in the direction of the director, which in itself would give rise to a lower linear expansion parallel to the director, but additionally, upon heating to above the glass-transition temperature, the order parameter decreases, which leads to contraction when the temperature rises. Consequently, the linear thermal coefficient is negative parallel to the orientation direction, and the perpendicular thermal expansion is larger and keeps increasing with temperature. This effect is shown in Figure 8 and is in fact the origin of many thermoresponsive and, indirectly, photoresponsive actuators. Above $T_{\mathrm{g}}$ at around $350 \mathrm{~K}$, the anisotropy of the linear expansion becomes rather large. There is a minor influence of the polymerization temperature and the presence of a lateral substituent. Higher polymerization temperature means a somewhat less ordered network, which slightly reduces the anisotropic effect. ${ }^{22}$ The lateral methyl substituent tends to enhance the effect somewhat, probably because of steric arguments.

\section{PATTERNED LC NETWORK COATINGS AND THEIR APPLICATIONS}

Optical Films and Coatings. An obvious application based on the anisotropic refractive indices is to use the polymer films as optical retarders to control the polarization state of transmitted light. Indeed, quarter-wave plates $(d \Delta n=\lambda / 4$ with $d$ being the thickness of the film and $\lambda$ being the wavelength of transmitted light) and half-wave plates ( $d \Delta n=$ $\lambda / 2$ ) are easily made by controlling the thickness and birefringence. The monomers are aligned uniaxially at an orientation layer, either rubbed polyimide or a photoalignment film, prior to polymerization. ${ }^{24,25}$ An LC network retarder application that presently became popular is the use of patterned quarter-wave plates for $3 \mathrm{D}$ television. ${ }^{26}$ For this application, the director of the LC network is controlled by the use of a photoalignment layer applied to a birefringence-free polymer substrate (usually cellulose triacetate). The molecular orientation is controlled by the local exposure of the photoalignment layer through a line mask. The orientation of

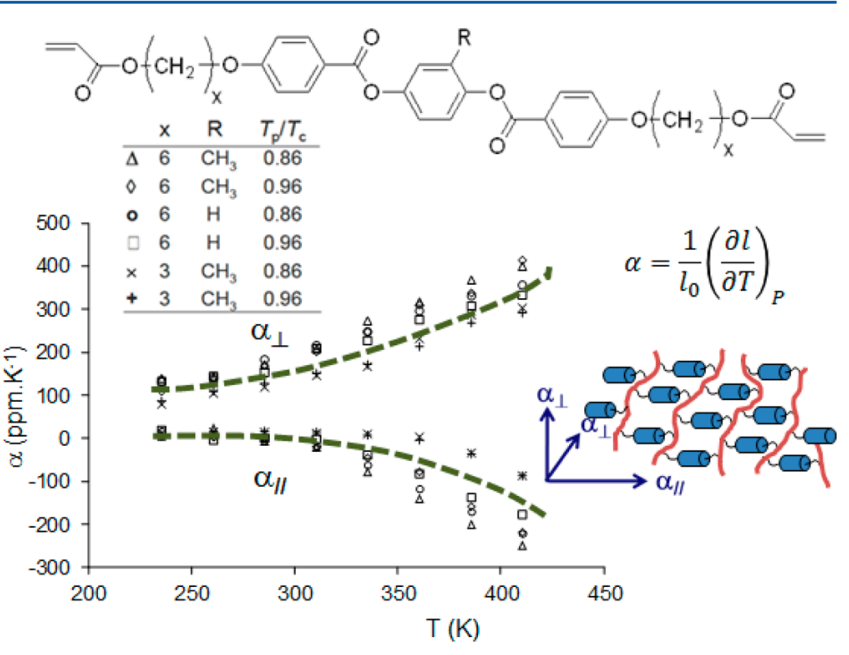

Figure 9. Linear thermal expansion coefficients of uniaxially aligned LC networks. The LC networks were made with some structural variations with respect to spacer length and core substituents and at various reduced temperatures $\left(T_{\mathrm{p}} / T_{\mathrm{c}}\right)$, with $T_{\mathrm{p}}$ being the polymerization temperature and $T_{c}$ being the transition temperature of the monomer to the isotropic phase. ${ }^{21-23}$

the subsequently applied and cured LC coating is zigzag-wise alternating orthogonally with a line width equal to the pixel size. The director of both line types is $45^{\circ}$ with respect to the polar axis at the front the LCD screen. This generates circularly polarized light with alternating handedness. In combination with circularly polarizing glasses, this provides distinguished information for the left and right eyes.

The strength of the technology expresses itself in the application as corrective retarder films that are presently being used in twisted nematic $\left(\mathrm{TN}\right.$; molecular rotation of $\left.90^{\circ}\right)$ and supertwisted nematic (STN; molecular rotation of 180,240 , or $270^{\circ}$ ) displays. The viewing angle performance of TN films can be improved by tilted retarders that are organized in a splay configuration with a polyimide-induced planar orientation on one side and a surface-tension-driven tilted orientation on the other side of the LC network film. ${ }^{27,28}$ Although a viewing angle improvement can be achieved by both rodlike and discotic LC networks, most commercial devices make use of the latter. ${ }^{29,30}$ For STN displays, a film containing an LC network with the same but opposite supertwist is added to the optical 


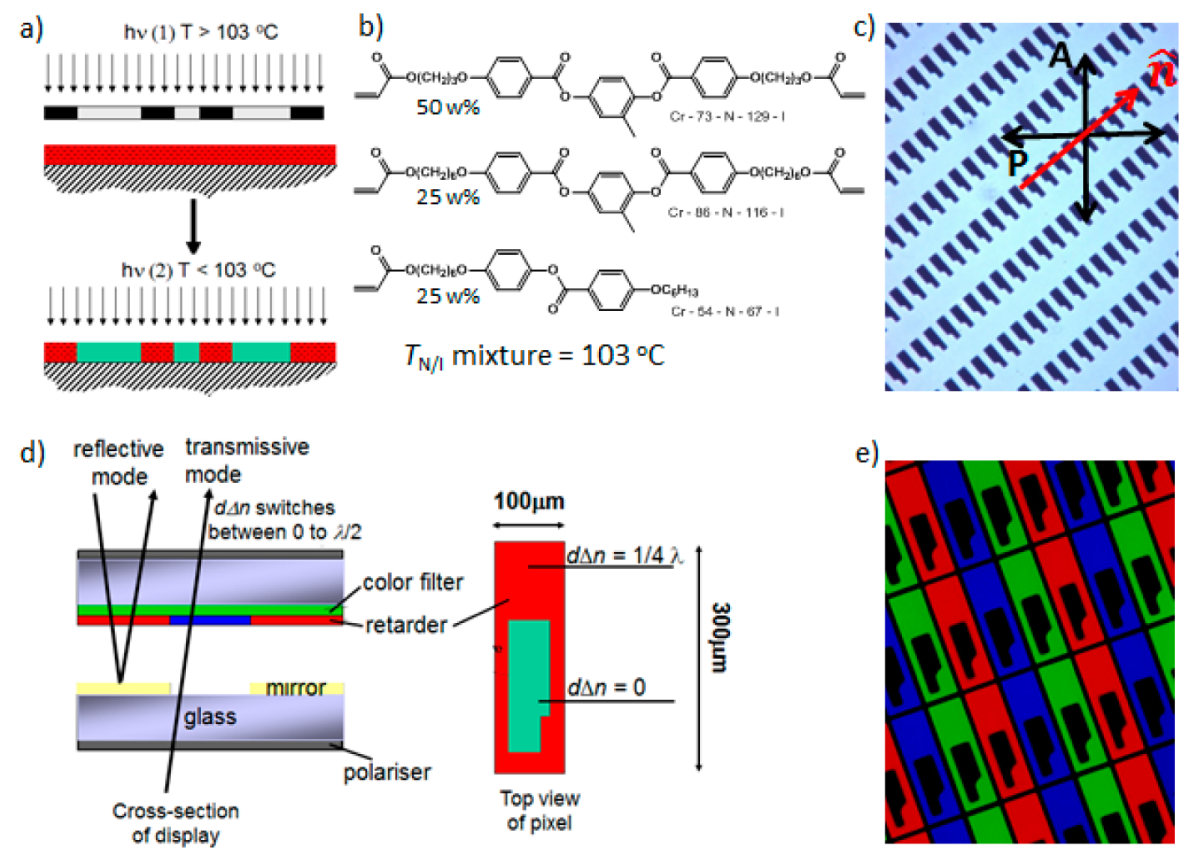

Figure 10. Fabrication of a patterned retarder for a transflective display. (a) The two-step photopolymerization below and above the nematic-toisotropic transition temperature produces a patterned quarter-wave retardation area next to the isotropic area. (b) An example of a mixture of reactive mesogens. (c) The patterned retarder between crossed polarizers as observed by polarization microscopy. Bright fields are birefringent, and black areas are isotropic. (d) The application of the patterned retarder in the transflective display with a quarter-wave function on the reflective mirror and an isotropic area in the transmissive area. (e) A polarization microscrope picture of the transflective display cell including the patterned retarder and the color filter. The process has been described in detail in refs $32-35$.

stack. These films solve the color problems that STN displays intrinsically have. ${ }^{31}$ A special feature is that the temperature dependence of the liquid crystal in the display cell is mimicked in the polymer film by controlling the cross-link density of the LC network.

Another application that nicely demonstrates the versatility of LC networks is their application in patterned retarders for transflective displays ${ }^{32,33}$ (Figure 10). In this display type, meant to operate under dark and under very bright ambient conditions, each pixel is provided with an internal mirror just below the liquid crystal. This mirror reflects ambient light in the open state of the pixel. The mirror is provided with a small hole that transmits light from the back (e.g., provided by an LED-driven back light). The objective here is to apply a retarder in the display cell that has zero retardation at the location in the pixel where light is transmitted through the semitransparent mirror on the back-light side of the display cell. At the location in the pixel where light is reflected at the mirror, the film has a quarter-wave retardation (Figure 10d). The light that is transmitted twice through the LC layer due to reflection (off-state/bright appearance) is compensated for by the retarder layer. It is therefore brought into the open state, and this part of the pixel has the same appearance as the light that is transmitted through the aperture in the mirror. Also in the on state (black appearance), the linear polarized light is converted into circularly polarized light by the quarter-wave function and switches handedness upon reflection which therefore becomes absorbed by the top polarizer film after having passed the quarter-wave function for the second time. Thereby this black state matches the black state of the transmissive mode. ${ }^{34,35}$ The patterned optical retarder was conveniently made by polymerizing the LC monomer mixture in two stages (Figure 10a): first by UV exposure through a photomask at a temperature where the LC monomer was in its nematic state to provide the quarter-wave function and a second UV exposure after heating the remaining monomer to its isotropic state, thus providing the nonbirefringent area which is located above the open area of the patterned mirror.

Presently, LC networks are being used in most flat panel LC television applications. Depending on the LC principle, the LC network is used as a retarder to improve on contrast (in-plane switching (IPS) for LCTV), stabilize the in-cell liquid crystal orientation (polymer-stabilized vertically aligned nematic (PSVAN) for LCTV), or improve the in-viewing angle (twisted nematic (TN) for monitor displays). Besides these wellestablished purely optical applications, new applications are coming up making use of the opto-mechanical effects based on triggered changes in the degree of molecular order. An example is discussed in the next section.

Light-Responsive Liquid Crystal Polymer Surfaces. When a liquid crystal network film is modified with co-crosslinked azobenzene moieties, the order parameter can be reduced by illuminating with UV light. The extended trans conformation of the azobenzene is converted to the bent cis conformation and affects the order of the surrounding LC moieties. This leads to a change of the molecular order of the network and sometimes even to reorientation. ${ }^{36-41}$ As a result, the dimensions of the film change with contraction along the director and expansion to the two perpendicular directions. Normally these effects are rather small. But when applied in combination with a gradient in intensity over the thickness of the film the effects can be amplified by transferring linear contraction to a bending deformation. Even better control over the deformation, with an outlook to make complex, origamitype shape changes possible in free-standing films, can be achieved by the use of director gradients and director patterns. $^{42}$ Also one can make use of the polarizationdependent absorption of the azobenzene compound to redirect 
1

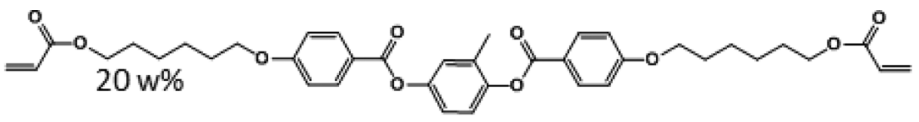

2

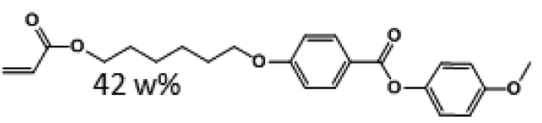

3

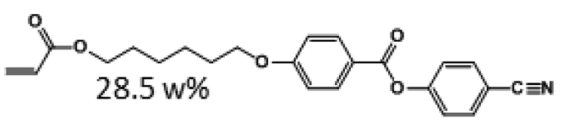

4

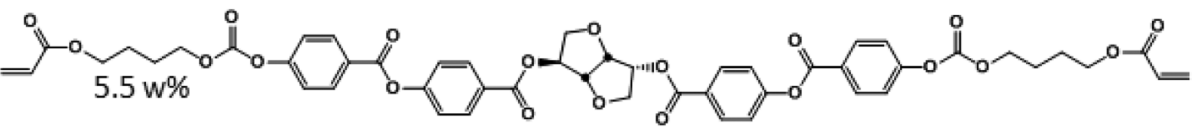

5

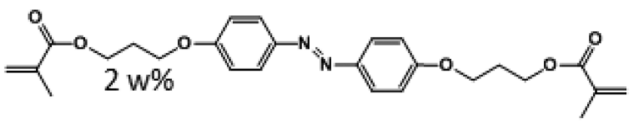

6

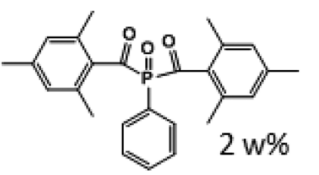

Figure 11. Composition of an LC monomer mixture that forms chiral nematic network with patterned homeotropic area induced by a local electrical field that, after polymerization, switches its surface profile.
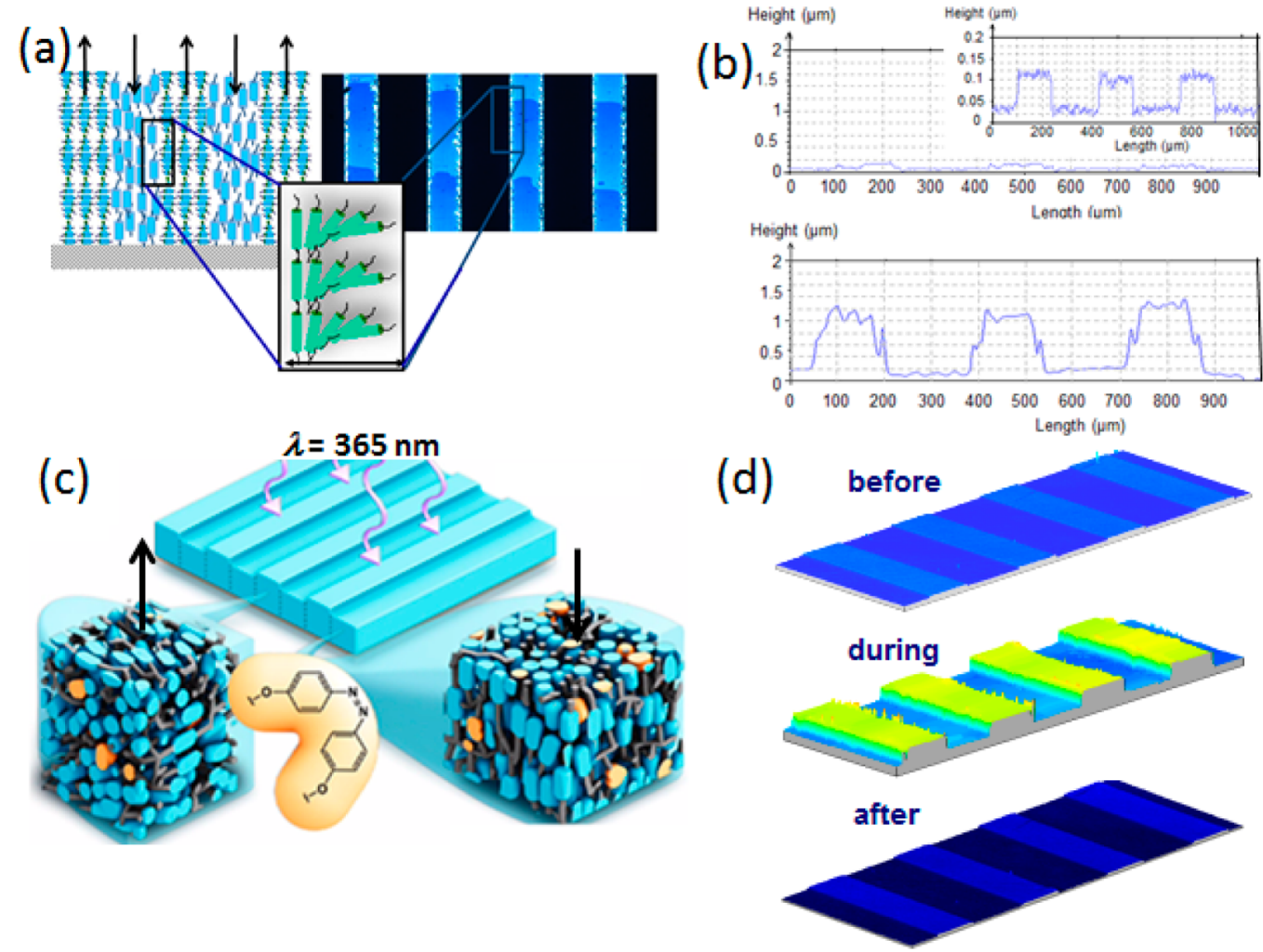

Figure 12. Principle and measurements of surface dynamics in a patterned chiral nematic network. (a) Schematic representation of the LC order in the patterned stripes and its confirmation by polarization microscopy. (b) A surface profile of the film as made and during exposure to UV light. (c) An artist's impression of the deformation at the surface of the film upon exposure to UV light. (d) Three-dimensional images of surface topographies in the original state (top) and during illumination with UV light (middle) and after removal of the UV source (bottom).

deformation by the direction of polarization as is shown by Ikeda et al. ${ }^{38}$

A relatively new effect in controlling shape transformations of potentially even more interest for future applications is the formation of surface topographies. ${ }^{43}$ One method to realizing this is to make use of the reorientation of azobenzene attached as a side group in an LC side-chain polymer. ${ }^{44}$ This goes beyond the purpose of this paper where we limit ourselves to patterned structures. Here we will emphasize dynamic surface topographies as created by director patterns in an LC polymer 
network. It is a representative example on how by carefully controlling composition and director patterns new properties can be added to LC network coatings, leading to features that are unknown for other materials. For this purpose, a composition is chosen as shown in Figure 11. Each component in this mixture has its own function. Monomers $\mathbf{1}$ and $\mathbf{2}$ form the nematic basis of the mixture. Their ratio is chosen to achieve an optimized cross-link density. This controls the stiffness of the network and affects the response behavior of the polymer with respect to speed and reversibility. Monomer 3 was added because it converts the negative dielectric anisotropy of monomers $\mathbf{1}$ and $\mathbf{2}$ into a positive dielectric anisotropy. A positive dielectric anisotropy enables alignment by an external electrical field. The chiral center of monomer 4 induces the chiral nematic phase in the monomer mixture. The advantage of using the chiral nematic LC molecular order is that it provides in-plane symmetry in the polymer coating with a better predictable photomechanical behavior. Monomer $\mathbf{5}$ is responsible for the photoresponsive nature of the film by its ability to change conformation when addressed with $365 \mathrm{~nm}$ light. Photoinitiator 6 is chosen because it forms free radicals to initiate the photo-cross-linking reaction by exposure with light $>400 \mathrm{~nm}$. This is important as at these wavelengths the azobenzene monomer keeps its trans conformation during the polymerization process.

A thin coating of typically 5 to $10 \mu \mathrm{m}$ is made by capillary filling of a glass cell that is provided with an indium tin oxide (ITO) layer on one side and a patterned (ITO) coating on the opposite side. In the monomeric state of the mixture, planar (chiral) alignment is controlled by rubbed polyimide and perpendicular alignment by a local electrical field with the ac voltage of $60 \mathrm{~V}$ at the ITO patterns. This structure is frozen in by exposure with visible light blocking UV light of $<405 \mathrm{~nm}$ using a cutoff filter. After removal of the top plate, the film shows a minor surface relief of $80 \mathrm{~nm}$ related to the imprints of the patterned ITO electrode. When observed by polarization microscopy between crossed polarizers, black lines of the homeotropic (perpendicular oriented) polymer are alternated with the bright lines of the chiral nematic planar areas. The two orientation areas are connected by a narrow bright area which is related to a transition between the two types of molecular alignment (Figure 12).

When the patterned LC network is attached to a stiff surface rather than being free-standing, UV-induced changes in the order parameter result in the formation of the surface relief. The two types of molecular order have opposite photomechanical responses, the combination of which results in larger effects than those studied previously. ${ }^{45}$ The surface deformation, expressed as the height difference between the activated regions and the nonactivated regions divided by the initial film thickness, can reach values of up to $24 \%$. Figure 12 shows an example of a patterned film which upon exposure to UV light forms surface structures of around $0.4 \mu \mathrm{m}$. When the light source is removed, the film immediately relaxes back to its initial flat state.

The origin of this significant change in surface topography is explained by a combination of effects. First, it has been demonstrated that the density reduces considerably when the azobenzene molecule changes its conformation from the trans to cis state. ${ }^{46,47}$ The planar oriented areas absorb the UV light more efficiently than the homeotropic area, which means that they benefit more from this volume expansion. On top of that, the reduction of the order parameter expands the film in the direction perpendicular to the director. This means that in the planar chiral area expansion predominantly takes place out of plane of the film. Simultaneously, the expansion in the homeotropic area takes place in the plane of the film with a tendency toward contraction out of the plane. The resulting 3D interferometer measurements are shown in Figure 12d. The back reaction to the planar state proceeds immediately when the light is switched off and takes several tens of seconds.

Responsive surface topographies can find a variety of applications in modern technologies, such as controlled wettability, autonomous lenses, and haptic surfaces. For example, switching surface structures in microfluidic devices may induce the mixing of laminarly flowing liquids. The lotusflower-inspired self-cleaning surface can be activated by changing the surface from flat to micrometer-sized topographies. We also anticipate the dynamic surface topographies to be employed for tribological applications where the friction can be switched between high and low friction states and in optical applications where we may switch the scattering or diffractive state of a surface.

\section{CONCLUSIONS AND PROSPECTS}

Liquid crystal networks have found their application in many optical applications. In particular, their use in television and monitor displays has been widely introduced. In the literature, many examples of LC monomers can be found which provide extensive possibilities to tailor the properties both of the monomers or monomer mixtures and of the polymers. The LC monomers can be processed either in the melt or from solution. Orientation takes place in their liquid crystal phase at treated interfaces or by means of an external field. We showed two examples of applications of patterned LC network coatings. The first one is a patterned optical retarder for a transflective display where areas with a quarter-wave retardation function are alternated with areas with zero optical retardation. The second application is a coating of which the surface structure is modulated by UV light. In this coating, areas with a planar chiral orientation are alternated with areas with a homeotropic orientation. Surface structures are reversibly being formed with a height $>20 \%$ of the initial coating thickness. We anticipate that this switchable surface is of interest for a variety of applications varying from liquid transport in microfluidics to light-tracking optical elements in solar energy.

\section{AUTHOR INFORMATION}

\section{Notes}

The authors declare no competing financial interest. Biographies

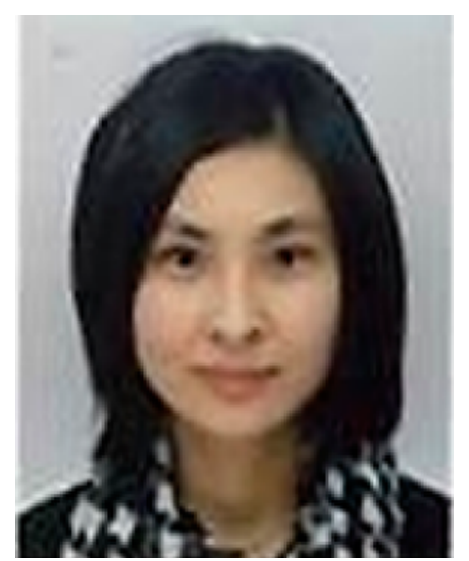


Danqing Liu studied at the University of Electronic Science \& Technology of China where she received her Bachelor's degree in 2006. In 2008, she received her Master's degree in electronic engineering at Delft University of Technology, The Netherlands. Her Ph.D. study of responsive polymers was conducted at Eindhoven University of Technology, Department of Mechanical Engineering, where she graduated in 2013. Presently she has a postdoctoral position at the same university in the Department of Chemical Engineering with Prof. Dirk J. Broer. Her present research is on surface dynamics.

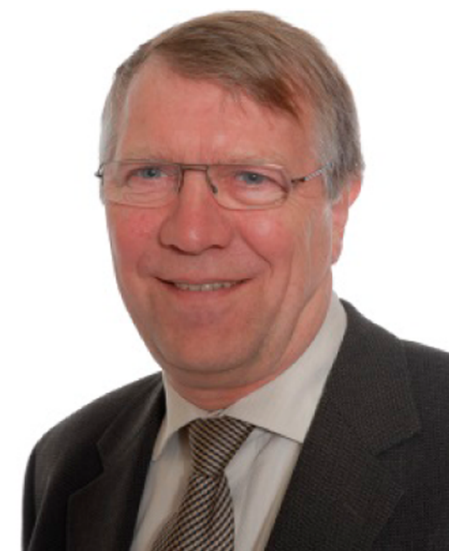

Dirk J. Broer is a polymer chemist and specialized in polymer structuring and self-organizing polymer networks. In 1973, he joined Philips Research (Eindhoven, The Netherlands), where he worked on manifold research topics such as vapor-phase polymerization, optical data storage, telecommunication fibers, and display optics. In 1990 and 1991, he worked at the DuPont Experimental Station (Delaware, USA) on nonlinear optical materials and the vapor-phase deposition of $\pi$-conjugated polymers. He started his work on liquid crystal materials in 1985, developing the process of in situ photopolymerization of liquid crystal monomers to form densely cross-linked and monolithically ordered liquid crystal networks. Starting in 1991, he developed at Philips Research optical films for LCD enhancement, and in 2000, he started his work on new manufacturing technologies of LCDs for large-area displays and electronic wallpaper. From 2003 to 2010, he was a senior research fellow and vice president at the Philips Research Laboratories specializing in biomedical devices and applications of polymeric materials. In 1996, he was appointed as part-time professor at Eindhoven University covering research topics such as liquid crystals, polymer waveguides, solar energy, organic semiconductors, nanolithography, soft lithography, and polymer actuators for biomedical microfluidic systems. In 2010, he was appointed a fulltime professor at Eindhoven and currently chairs the Department of Functional Organic Materials and Devices with a research emphasis on clean technologies in energy harvesting, water treatment, and healthcare. Prof. Broer is a member of the Royal Netherlands Academy of Arts and Sciences (KNAW). In total, he has around 240 publications in peer-reviewed journals and 120 U.S. patents.

\section{ACKNOWLEDGMENTS}

The results presented on the dynamic surface topographies are part of a research program financed by the Dutch Polymer Institute (DPI), project no. 775 .

\section{REFERENCES}

(1) Broer, D. J.; Boven, J.; Mol, G. N.; Challa, G. In-situ photopolymerization of oriented liquid-crystalline acrylates, 3. Oriented polymer networks from a mesogenic diacrylate. Makromol. Chem. 1989, 190, 2255.
(2) Broer, D. J.; Hikmet, R. A. M.; Challa, G. In-situ photopolymerization of oriented liquid-crystalline acrylates, 4. - Influence of a lateral methyl substituent on monomer and oriented network properties of a mesogenic diacrylate. Makromol. Chem. 1989, 190, 3201.

(3) Broer, D. J.; Mol, G. N.; Challa, G. In-situ photopolymerization of oriented liquid-crystalline acrylates, 5. - Influence of the alkylene spacer on the properties of the mesogenic monomers and the formation and properties of oriented polymer networks. Makromol. Chem. 1991, 192, 59.

(4) Broer, D. J. Photoinitiated Polymerization and Crosslinking of Liquid Crystalline Systems. In Radiation Curing in Polymer Science and Technology; Fouassier, J. P., Rabek, J. F., Eds.; Elsevier Science Publishers Ltd.: London, 1993; Vol. 3, Chapter 12, p 383.

(5) Broer, D. J.; Heynderickx, I. Three-dimensionally-ordered polymer networks with a helicoidal structure. Macromolecules 1990, 23, 2474.

(6) Schmitt, G.; Giesa, R.; Schmidt, H.-W. Cholesteric networks based on lyotropic mixtures. ChemPhysChem 2003, 4, 505.

(7) Kitzerow, H. S.; Schmid, H.; Ranft, A.; Heppke, G.; Hikmet, R. A. M.; Lub, J. Observation of blue phases in chiral networks. Liq. Cryst. 1993, 14, 911.

(8) Lub, J.; Broer, D. J.; Hikmet, R. A. M.; Nierop, K. G. J. Synthesis and photopolymerization of cholesteric liquid crystalline diacrylates. Liq. Cryst. 1995, 18, 319.

(9) Broer, D. J. Creation of supramolecular thin film architectures with liquid-crystalline networks. Mol. Cryst. Liq. Cryst. Sci. Technol, Sect. A 1995, 261, 513.

(10) Ullett, J. S.; Schultz, J. W.; Chartoff, R. P. Novel liquid crystal resins for stereolithography - processing parameters and mechanical analysis. Rapid Prototyping J. 2000, 6, 8.

(11) Demus, D.; Zaschke, H. Flüssige Kristalle in Tabellen II; VEB Deutcher Verlag für Grundstoffindustrie: Leipzig, 1984.

(12) Lub, J.; Broer, D. J. Densely Crosslinked Liquid Crystal Networks by Controlled Photopolymerization of Ordered Liquid Crystal Monomers - Properties and Applications. In Cross-Linked Liquid Crystalline Systems; Broer, D. J., Crawford, G. P. C., Zumer, S., Eds.; CRC Press: Boca Raton, FL, 2011; Chapter 1.

(13) Keller, P.; Thomsen, D. L.; Li, M.-H. Facile and inexpensive synthesis of e $\alpha, \beta, \dot{\beta}$,-deuterated liquid crystalline and classical acrylate monomers. Marcomolecules 2002, 35, 581.

(14) Lub, J.; Broer, D. J.; Hikmet, R. A. M.; Nierop, K. G. J. Synthesis and photopolymerization of cholesteric liquid crystalline diacrylates. Liq. Cryst. 1995, 18, 319.

(15) Kuball, H. G., Hofer, T. Chirality in Liquid Crystals. SpringerVerlag: New York, 2001; p 74.

(16) Broer, D. J.; Lub, J.; Mol, G. N. Wide-band reflective polarizers from cholesteric polymer networks with a pitch gradient. Nature 1995, 378, 467.

(17) Mitov, M. Cholesteric liquid crystals with a broad light reflection band. Adv. Mater. 2012, 24, 6260.

(18) Finkelmann, H.; Brand, H. R. Liquid crystalline elastomers - A class of materials with novel properties. Trends Polym. Sci. 1994, 2, 222.

(19) Ohm, C.; Brehmer, M.; Zentel, R. Liquid Crystalline Elastomers as Actuators and Sensors. Adv. Mater. 2010, 22, 3366.

(20) Hikmet, R. A. M.; Zwerver, B. H.; Broer, D. J. Anisotropic polymerization shrinkage behaviour of liquid-crystalline diacrylates. Polymer 1992, 33, 89.

(21) Hikmet, R. A. M.; Broer, D. J. Dynamic mechanical properties of anisotropic networks formed by liquid crystalline acrylates. Polymer 1991, 32, 1627.

(22) Broer, D. J.; Mol, G. N. Anisotropic Thermal Expansion of Densely Cross-Linked Oriented Polymer Networks. Polym. Eng. Sci. 1991, 31, 625.

(23) Mol, G. N.; Harris, K. D.; Bastiaansen, C. W. M.; Broer, D. J. Thermo-mechanical responses of liquid-crystal networks with a splayed molecular organization. Adv. Funct. Mater. 2005, 15, 1155. 
(24) Schadt, M.; Seiberle, H.; Schuster, A. Optical patterning of multi-domain liquid crystals with wide viewing angles. Nature 1996, 381, 212.

(25) Schadt, M.; Seiberle, H.; Schuster, A.; Kelly, S. M. Photogeneration of linearly polymerized liquid crystal aligning layers with integrated optically patterned retarders and color filters. Jpn. J. Appl. Phys., Part 1 1995, 34, 3240.

(26) Mun, B.-J.; Lee, G.-D. Optical structure for a three-dimensional liquid-crystal cell using a wide-band and wide-view half-wave retarder. J. Korean Phys. Soc. 2013, 62, 40.

(27) Van de Witte, P.; Stallinga, S.; Van Haaren, J. A. M. M. Viewing angle compensators for liquid crystal displays based on layers with a positive birefringence. Jpn. J. Appl. Phys.,Part 1 2000, 39, 101.

(28) Van de Witte, P.; Van Haaren, J.; Tuijtelaars, J.; Stallinga, S.; Lub, J. Preparation of retarders with a tilted optic axis. Jpn. J. Appl. Phys., Part 1 1999, 38, 748.

(29) Mori, H.; Itoh, Y.; Nishiura, Y.; Nakamura, T.; Shinagawa, Y. Performance of a novel optical compensation film based on negative birefringence of discotic compound for wide-viewing-angle twistednematic liquid-crystal displays. Jpn. J. Appl. Phys. 1997, 36, 143.

(30) Mori, $\mathrm{H}$. The wide view (WV) film for enhancing the field of view of LCDs. J. Display Technol. 2005, 1, 179.

(31) Heynderickx, I.; Broer, D. J. The used of cholesterically ordered polymer networks in practical applications. Mol. Cryst. Liq. Cryst. 1991, 203, 113.

(32) Lub, J.; Broer, D. J.; Wegh, R. T.; Peeters, E.; van der Zande, B. M. I. Formation of optical films by photo-polymerisation of liquid crystalline acrylates and application of these films in liquid crystal display technology. Mol. Cryst. Liq. Cryst. 2005, 429, 77.

(33) van der Zande, B. M. I.; Steenbakkers, J.; Lub, J.; Leewis, C. M.; Broer, D. J. Mass transport phenomena during lithographic polymerization of nematic monomers monitored with interferometry. J. Appl. Phys. 2005, 97, 123519.

(34) Roosendaal, S. J.; Van der Zande, B. M. I.; Nieuwkerk, A. C.; Renders, C. A.; Osenga, J. T. M.; Doornkamp, C.; Peeters, E.; Bruinink, J.; van Haaren, J. A. M. M. Technologies towards patterned optical foils. SID Symp. Digest Tech. Pap. 2003, 78.

(35) Van der Zande, B. M. I.; Doornkamp, C.; Roosendaal, S. J.; Steenbakkers, J.; Op’t Hoog, A.; Osenga, J. T. M.; Van Glabbeek, J. J.; et al. Technologies towards patterned optical foils applied in transflective LCD's. J. Soc. Inf. Display 2005, 13, 627.

(36) Warner, M.; Modes, C. D.; Corbett, D. Curvature in nematic elastica responding to light and heat. Proc. R. Soc. A 2010, 466, 2975.

(37) Evans, J. S.; Ackerman, P. J.; Broer, D. J.; Lagemaat, J.; Smalyukh, I. I. Optical generation, templating, and polymerization of three-dimensional arrays of liquid-crystal defects decorated by plasmonic nanoparticles. Phys. Rev. E 2013, 87, 032503-.

(38) Yu, Y.; Nakano, M.; Ikeda, T. Photomechanics: Directed bending of a polymer film by light. Nature 2003, 425, 145.

(39) White, T. J.; Serak, S. V.; Tabiryan, N. V.; Vaia, R. A.; Bunning, T. J. Polarization-controlled, photodriven bending in monodomain liquid crystal elastomer cantilevers. J. Mater. Chem. 2009, 19, 1080.

(40) Camacho-Lopez, M.; Finkelmann, H.; Palffy-Muhoray, P.; Shelley, M. Fast liquid-crystal elastomer swims into the dark. Nat. Mater. 2004, 3, 307.

(41) Van Oosten, C. L.; Bastiaansen, C. W. M.; Broer, D. J. Printed artificial cilia from liquid-crystal network actuators modularly driven by light. Nat. Mater. 2009, 8, 677.

(42) de Haan, L. T.; Sanchez-Somolinos, C.; Bastiaansen, C. M. W.; Schenning, A. P. H. J.; Broer, D. J. Engineering of complex order and the macroscopic deformation of liquid crystal polymer networks. Angew. Chem., Int. Ed. 2012, 51, 12469.

(43) Liu, D.; Bastiaansen, C. W. M.; den Toonder, J.M..J.; Broer, D. J. Photo-switchable surface topologies in a chiral-nematic polymer. Angew. Chem., Int. Ed. 2012, 51, 892.

(44) Gritsai, Y.; Goldenberg, L. M.; Kulikovskaand, O.; Stumpe, J. 3D structures using surface relief gratings of azobenzene materials. J. Opt. A: Pure Appl. Opt. 2008, 10, 125304.
(45) Sousa, M. E.; Broer, D. J.; Bastiaansen, C. W. M.; Freund, L. B.; Crawford, G. P. Isotropic "islands" in a cholesteric "sea": patterned thermal expansion for responsive surface topologies. Adv. Mater. 2006, $18,1842$.

(46) Liu, D.; Broer, D. J. Liquid crystal polymer networks: switchable surface topographies. Liq. Cryst. Rev. 2013, 1, 20.

(47) Liu, D.; Bastiaansen, C. W. M.; den Toonder, J. W. M.; Broer, D. J. Light-induced formation of dynamic and permanent surface topologies in chiral-nematic polymer networks. Macromolecules 2012, 45,8005 . 